\title{
DEL KERO COLONIAL AL KERO REPUBLICANO
}

\author{
From Colonial Kero to Republican Kero
}

\author{
Elard Vladimir Chaiña Flores ${ }^{1}$
}

\begin{abstract}
RESUMEN
El presente artículo se ocupa de los cambios en la forma y ornato del keroocurrido entre los siglos XVIII y $X X$ en el contexto geográfico del actual departamento de Puno. El análisis iconológico y de variaciones estilísticas encontró que después del movimiento social de Túpac Amaru II, los keros se hispanizaron en desmedro de la tradición inca.
\end{abstract}

Palabras clave: Kero, arte popular, iconografia, iconología, variaciones estilísticas.

\begin{abstract}
This article deals with the changes in the form and decoration of the kero occurred between the eighteenth and twentieth centuries in the geographical contex the present department of Puno. The iconological and stylistic variations analysis found that after Tupac Amaru II's social movement, keros hispanicized detrimenting Inca tradition.
\end{abstract}

Keywords: Kero, folk art, iconography, iconology, stylistic variations.

\section{INTRODUCCIÓN}

La investigación analizó e interpretó los cambios en la forma y ornato del vaso ceremonial usados para reforzar los lazos de cohesión en las actividades sociales denominado kero o quero, entre los siglos XVIII y XX en el ámbito geográfico del actual departamento de Puno.

El 4 de noviembre de 1780 se inicia el movimiento social de Túpac Amaru II, fue el proyecto nacional de la aristocracia indígena, y tuvo como centros de esta tendencia nacionalista, a las escuelas de caciques principalmente del Cusco, "Por su ideología neo-inca, se consideraban descendientes de los verdaderos soberanos del Perú" (Golte, 1980, p. 184). José Gabriel Túpac Amaru II encarnará esta ideología, este "nacionalismo neo-Inca fue la fuente ideológica más evidente para el levantamiento de Túpac Amaru" (Walker, 2013, p. 45), reforzado por las manifestaciones culturales que permitió mantener vívido el concepto de identidad Inca, alegóricas al Imperio Inca o de tradición Inca; lo que permitió que se convirtiera en un movimiento de corte indigenista que propugnaba el gobierno de la descendencia Inca.

Tras el fallido intento del movi-

${ }^{1}$ Doctor en Ciencias Sociales, Magister en Arte, Licenciado en Arte. Docente de la Facultad de Ingenieria Civil, Arquitectura y Geotecnia de la Universidad Nacional Jorge Basadre Grohmann. Tacna-Perú.

Correoelectrónico:ee012126@hotmail.com 
miento de Túpac Amaru II, las autoridades coloniales eliminaron a la nobleza indígena y acrecentaron la represión contra lo andino. Areche pidió la anulación "de todo vestigio artístico, folclórico y cultural, así como de los privilegios y prácticas ceremoniales que evocaban la memoria de los antiguos emperadores Incas" (Cahill, 2006, p. 90). Las manifestaciones culturales se vieron afectadas por mantener en el imaginario colectivo el concepto de lo Inca, como los keros; los esfuerzos para erradicar cualquier recuerdo ancestral dio como resultado el inicio del cambio en la forma y ornato de los keros que hoy se encuentran en pleno proceso de desaparición.

\section{El Kero}

Kero o Quero, del quechua: qiru, moderno q'iru, madera, frecuentemente escrito como kero, es un vaso ceremonial, habitualmente de madera, de forma troncocónica, más ancho por la boca que por la base, típico de varias culturas sur andinas. Mencionado ya en Lexicón o Vocabulario de la lengua general del Perú de 1560, Fray Domingo de Santo Tomas (2006): “Q'IRU: cuba de madera [...] cuba para vino" (p. 434); en 1608 es mencionado como "Quero: Vaso de madera" (Gonzalez Holguín, 1989, p.305); y en 1612 en aymara también se conoció como "Qiru: vaso para beber, de madera o plata, de cualquier hechura que sea" (Bertonio, 2004, p. 593).

Si bien quero significa madera y esta forma de vasija se confeccionaba principalmente en este material "los "keros", realizados en duras maderas y ornamentados con solida pintura" (Sabogal, 1952, p. 12), también se hacían de arcilla, "sencilla y sin decoración; los casos excepcionales exhiben líneas incisas en forma de grecas horizontales" (Matos, 1999, p. 127-128); de plata como menciona Ludovico (2004): "Vaso para beber, de madera o plata, de cualquier hechura que sea. + Akilla: es lo mismo si es de plata" (p. 593); también existieron "los "keros" de oro incaicos, dicen los cronistas que fueron de hoja gruesa, muy hermosa y que llegaron a un peso de más de dos kilogramos", (Sabogal, 1952, p. 12).

Estos vasos son siempre un par, un vaso era para un individuo y el otro para invitar a otra persona o deidad a beber juntas, "fueron hechos para ser usados en los brindis ceremoniales que contribuian a reforzar los lazos de cohesión en las actividades sociales, especialmente las vinculadas con la familia, la economía, la política, la religión" (Koun, 2003, p. 213).

El kero Inca se deriva formalmente de los keros tiahuanacotas. Se trata de un vaso de base plana y paredes divergentes que muchas veces tienen un resalte o argolla en su parte media. En algunos casos tiene un asa en forma de un animal que se encarama sobre el borde, siendo alguno de estos vasos antropomorfos, zoomorfos.

Los keros eran generalmente decorados con lujo y pintado a mano los diseños geométricos que siguen a las técnicas tradicionales de alfarería. Otros, sin embargo, pueden ser pintados con escenas narrativas que podrían ser acontecimientos históricos. "Los inkas aprendieron la técnica de pintar con 'laca' sobre madera poco antes del contacto con los europeos. Esta habilidad alcanzó notable desarrollo a fines de los siglos XVII y XVIII, cuando comienzan a producirse los "vasos de colores", con representaciones complejas de temas de intrincado simbolismo, en los que los artistas indígenas dieron cauce a sus habilidades pictóricas" (Koun, 2003, p. 213). Así mismo, Teresa Gisbert (2008) menciona que en la colonia "los keros adquieren su carácter policromo y desde entonces su 
superficie se divide en tres partes: la inferior, decorada con flores, generalmente kantutas; la media, decorada con «tocapus»; en tanto que la parte superior del kero muestra temática específica" (p. 86-87).

Formalmente, los keros responden a cuatro grupos:

a) Geométrico - inciso.

b) Virreinal - formal (arcaico), generalmente "con dos pumas colocados diametralmente opuestos, los cuales emiten el arco iris de su boca, debajo del arco iris hay escenas referentes a los incas y por encima flores o figuras aisladas" (Gisbert et al., 2006, p. 145).

c) Virreinal - libre (tardío), "por influencia hispana, están decorados con elementos renacentistas como centauros y sirenas, otros tienen motivos heráldicos" (Gisbert, 2008, p. 87).

d) Republicanos.

En cuanto a la técnica, se puede clasificaren:

1) Simplemente incisos.

2) Incisos y pintados, rellenado con pasta coloreada las hendiduras. "Quero cuscusca o llimpisca. Pintado de colores" (González Holguín, 1989, p.306).

3) Simplemente pintados.

4) Claveteados con estaño y/o plata. "Titinchascaqquero o titihuanmorochasca. Vaso tachonado con plomo" (González Holguín, 1989, p. 305).

5) Escultóricos, con cabezas talladas, humanas o de pumas.

6) Con animales encaramados en el borde del vaso, ampliamente investigados por Horta (2013).

\section{Keros puneños}

Corresponden a la colección del Museo Municipal Carlos Dreyer - Puno, (22 piezas) y a la colección del autor (17 piezas) provenientes de diversas partes del departamento de Puno, y fueron clasificados por los íconos y formas que presentan. (Tabla 1).

El análisis de los keros determinó la iconografía más usada, siendo las más relevantes las escenas narrativas, tocapus y flores de cantuta; hojas de acanto y franja ondulante, lineal, zigzagueante, rombos eslabonados y hojas. Íconos que sumado a la forma de los keros (tabla 2), permitirán determinar variaciones estilísticas.

\section{Íconos de keros}

Para el entendimiento de la connotación de la forma y del ícono de los keros se desarrolla por un lado el análisis de escenas narrativas, tocapus y flores de cantuta, características que identifican un periodo determinado; por otro lado el análisis de hojas de acanto y franja ondulante, lineal, zigzagueante, rombos eslabonados y hojas.

\section{a. Ícono escenas - Tocapu -Flor de cantuta.}

Teniendo en cuenta que los keros incas fueron vasos de madera con decoración abstracta geométrica lineal incisa, "Producto de la invasión visual europea, se transformaron en otras piezas pintadas con diseños más realistas, miméticos y policromos que sus predecesores inkaicos, que en esos momentos se encontraban ordenados dentro de campos horizontales que contenían escenas narrativas figurativas" (Lizárraga, 2009, p. 38); “Esta habilidad alcanzó notable desarrollo $[\ldots]$, cuando comienzan a producirse los "vasos de colores", con representaciones complejas de temas de intrincado simbolismo" (Koun, 2003, p. 213).

De este modo, a partir de la segunda mitad del siglo XVI ocurrió un cambio en la iconografía de estos vasos de madera, pasando de imágenes geométricas abstractas a otras pictóricas figurati- 
Tabla 1. Iconos - Keros.

\begin{tabular}{|c|c|c|c|c|c|c|c|c|c|c|}
\hline KERO & $\begin{array}{c}\text { Escena - } \\
\text { Antropomorfo }\end{array}$ & $\begin{array}{c}\text { Escena - } \\
\text { Zoomorfo }\end{array}$ & Tocapu & $\begin{array}{l}\text { Flor / } \\
\text { cantuta }\end{array}$ & $\begin{array}{c}\text { Franja } \\
\text { lineal - } \\
\text { anillo }\end{array}$ & $\begin{array}{c}\text { Franja } \\
\text { rombos } \\
\text { eslabonados }\end{array}$ & $\begin{array}{c}\text { Franja } \\
\text { zigzagueante }\end{array}$ & $\begin{array}{c}\text { Franja } \\
\text { de } \\
\text { hojas }\end{array}$ & $\begin{array}{c}\text { Franja } \\
\text { ondulante }\end{array}$ & $\begin{array}{c}\text { Hoja } \\
\text { de } \\
\text { Acanto }\end{array}$ \\
\hline CMD001* & & & & & $x$ & $x$ & & & & \\
\hline CMD002 & $x$ & $\mathrm{x}$ & $x$ & $x$ & & & & & & \\
\hline CMD003 & & & $x$ & $x$ & $\mathrm{x}$ & & & & & \\
\hline CMD004 & $x$ & & $x$ & $x$ & $x$ & & & & & \\
\hline CMD005 & $x$ & $\mathrm{x}$ & $x$ & $x$ & & & & & & \\
\hline CMD006 & $x$ & & & $x$ & $x$ & & & & & \\
\hline CMD007 & & & $x$ & $x$ & $x$ & & & & & \\
\hline CMD008 & & & $x$ & & & & & & $x$ & $x$ \\
\hline CMD009 & & & & & $\mathrm{x}$ & & & & & \\
\hline CMD010 & & & & $x$ & & & $x$ & & & \\
\hline CMD011 & & & & & & & & & & \\
\hline CMD012 & & & & & $\mathrm{x}$ & & & & & $x$ \\
\hline CMD013 & & & & & $x$ & & & & & \\
\hline CMD014 & & & & & $x$ & & & & & \\
\hline CMD015 & & & & & & & & & & \\
\hline CMD016 & & $x$ & & & & & & & & \\
\hline CMD017 & & & & & $\mathrm{x}$ & $x$ & $x$ & & & \\
\hline CMD018 & & & & & & & & & & \\
\hline CMD019 & & & & & $x$ & & & & & \\
\hline CMD020 & & & & & $x$ & & & & & \\
\hline CMD021 & & & & $\mathrm{x}$ & & & $x$ & & & \\
\hline CMD022 & & $x$ & $\mathrm{x}$ & & $x$ & & $x$ & & & \\
\hline CPA001 * & & & & & $x$ & & & & & \\
\hline CPA002 & & & & & & & & & $\mathrm{x}$ & $\mathrm{x}$ \\
\hline CPA003 & & & & & & & & & & \\
\hline CPA004 & & & & & & & & & $x$ & $x$ \\
\hline CPA005 & & & & & $x$ & & & & & \\
\hline CPA006 & & & & & $x$ & & & & & \\
\hline CPA007 & & & & & & & & & $x$ & $x$ \\
\hline СРA008 & & & & & & $x$ & $x$ & $\mathrm{x}$ & & \\
\hline CPA009 & & & & & & & $x$ & & & \\
\hline CPA010 & & & & & $x$ & & & & & \\
\hline CРA011 & & & & & $x$ & & & & & \\
\hline CРA012 & & & & & $x$ & & & & & \\
\hline CРA013 & & & & & & & $\mathrm{x}$ & & & \\
\hline CРA014 & & & & & $x$ & & & & & \\
\hline CPA015 & & & & & $\mathrm{x}$ & & & & & \\
\hline $\begin{array}{l}\text { CPA016 } \\
\text { CPA017 }\end{array}$ & & & & & $x$ & & & & & \\
\hline
\end{tabular}

Fuente: E. V. Ch. F. Conteo de Iconos-Keros

${ }^{*}$ CMD001 $=$ Colección Museo Dreyer 001

${ }^{*}$ CPA001 = Colección Particular del Autor 001

vas. Así, y como parte de estas transformaciones pictóricas, surgieron los denominados queros de transición.

Las escenas temáticas comienzan a ser expresados en keros de tradición inca pero con "un idioma visual europeo. Algunas veces el préstamo es casi literal. Por ejemplo, la imagen del Inca, que es un elemento dominante en la iconografía de los qeros, [...] la figura está de pie en primer plano, en una pose de contrapostto, sosteniendo en una mano un escudo y un yauri o bastón en la otra" (Cummis, 2003, p. 55), escenas relacionadas con la pintura virreinal porque recoge las composiciones figurativas y las imágenes narrativas introducidas en el Perú desde España. 
Tabla 2. Clasificación Forma - Ornato

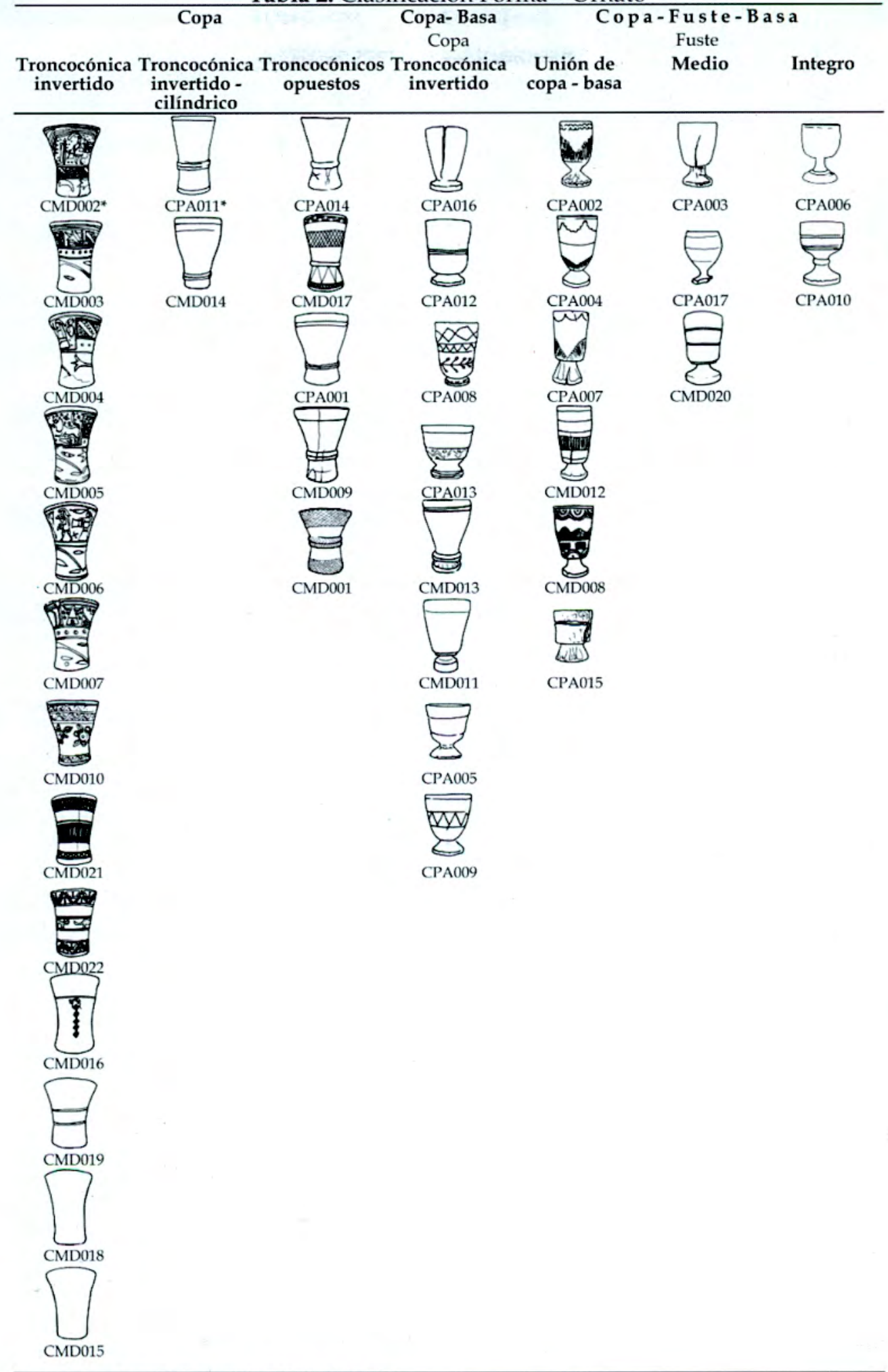

Fuente: Basado en el análisis de la forma (tabla 1).

${ }^{*} \mathrm{CMD}=$ Colección Museo; Dreyer. $\quad{ }^{*} \mathrm{CPA}=$ Colección Particular del Autor. 


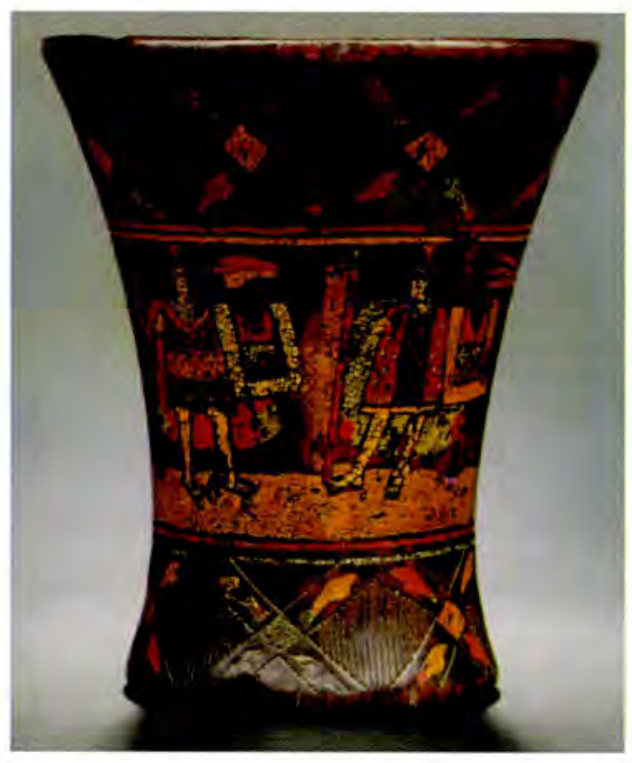

Figura 1. Kero. Escena temática: Inca. Siglo XVIII. Museo Inca. Universidad Nacional San Antonio Abad. Cusco. Fuente: Cummis (2003).

La decoración geométrica lineal de cuadrados concéntricos conocida como tocapus, dispuesta principalmente en textiles y keros. Estos tocapus se encontraban tejidos en los uncu, que solo usaba el Inca y algún curaca autorizado por él. "El valor ritual de estas piezas se desprende de la entrega que el Inka hacía de queros y aquillas, junto a textiles tipo toccapuccombi, como parte de los regalos más preciados a los curacas obedientes" (Lizárraga, 2009, p.40). Siendo la forma y color patrimonio de la elite, no estando a disposición de todos, solo como posibilidad de ascenso o reconocimiento de élites provinciales.

A comienzos del siglo XVII, tocapu nombraba a un tipo de trabajo textil de alta calidad, entendible porque recién los keros coloniales o de transición los utilizan con profusión.

La presencia de los tocapus en los queros coloniales o de transición, refuerza el prestigio del inca, de la nobleza de descendencia inca en la colonia.

La flor de cantuta (Cantua buxifolia), presente en los keros transición, CMD002, CMD003, CMD004, CMD005, CMD006, CMD007, CMD010, CMD021, constituye un motivo iconográfico muy usado en este periodo. La cantuta, del quechua qantu, es una especie vegetal nativa de Perú y Bolivia, considerada su Flor Nacional.

Los keros coloniales o de transición, son vasos troncocónicos de madera policromada, compuesta de iconografía de escenas temáticas, tocapus y flores de cantuta. Como corroborara Teresa Gisbert (2008): "es en la colonia que los keros adquieren su carácter policromo y desde entonces su superficie se divide en tres partes: la inferior, decorada con flores, generalmente kantutas; la media, decorada con «tocapus»; en tanto que la parte superior del kero muestra temática específica" (p.86-87).

\section{b. Ícono hojas deacanto-franja ondulante.}

El barroco fue principalmente el último estilo relacionado con el antiguo régimen virreinal, "la Revolución francesa y el pensamiento enciclopedista crearon un nuevo modo de pensar, fundamentado en la razón, del que el arte hizo reflejo. Por otra parte, el descubrimiento de las ruinas de Herculano en el año 1719 y de Pompeya en 1748, así como las teorías del alemán Wilckemann sobre arte grecorromano, provocó un auténtico boom del arte clásico" (Parramón, 2002, p. 52). El Neoclasicismo, encarnó los ideales de las nacientes repúblicas Europeas y este influjo estético se trasladó también a América y al Perú.

El Neoclasicismo se hace presente en Puno en la subsistente arquitectura civil, como el hoy denominado Arco Deustua, erigido por el prefecto, general Don Alejandro Deustua en 1847, como está escrito en el monumento, para con- 
memorar la "Gloria eterna a los héroes que en Junin y Ayacucho conquistaron para siempre la independencia de la patria", también decora el monumento aparte del escudo patrio, una alegoría a la libertad, con vara y gorro frigio - escudo con la leyenda "libe ta" que debió decir libertad.

La presencia en Puno del libro Traité Elémentaire Practique D’Architecture ou Étude des Cinq Ordres, edición del siglo XIX de Jacques Barozzio "Vignola" constituye "un libro claro, sistemático, erudito, bien estructurado y eminentemente práctico, donde la parte gráfica, con sus 29 láminas [...] fue asumido como un manual didáctico" (Urquiza y García, 2012, p. 70), documento muy popular que se volvió a poner de moda tras las influencias ideológicas de la naciente república.

Como se evidencia en el Colegio de Ciencias y Artes de Puno, el "local fue inaugurado el 2 de febrero de 1851" (Vera, 2008, p. 112), hoy colegio Gran Unidad Nacional San Carlos, con columnas de capitel compuesto; y una vivienda

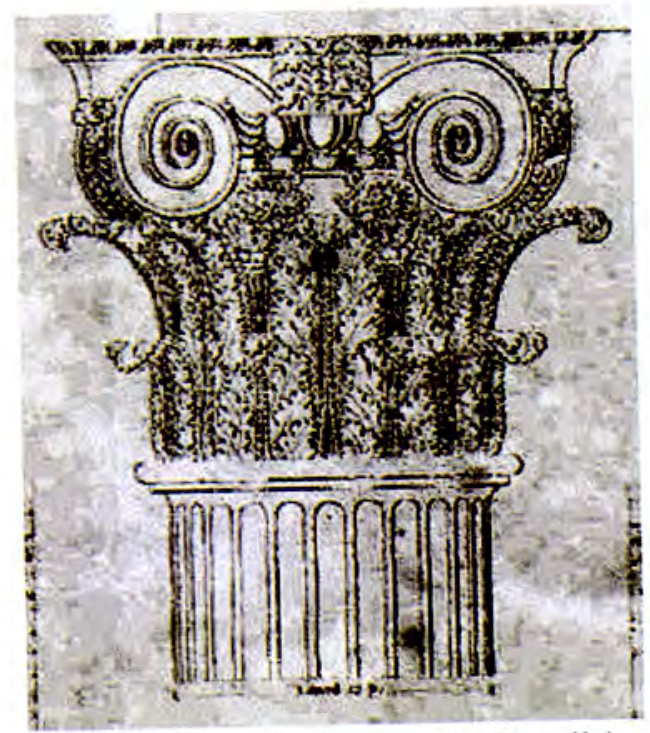

Figura 2. Capitel Compuesto (Detalle). Tomado de Jacques Barozzio de Vignole, Jacques. s/f: PL.LI. Traité Elémentaire Practique D'Architecture ou Étude des Cinq Ordres. particular adyacente al Parque Pino con columnas de capitel Corintio, ambos capiteles correctamente decorados con hojas de acanto. (Figura 2 y 3 ).

El Neoclasicismo presente en la arquitectura posee como motivo la hoja de acanto (Acanthusmollis), presente también en los keros CMD008, CMD012, CPA002, CPA004, CPA007, constituye un motivo iconográfico muy usado en la república, el acanto una especie vegetal, nativa de la región mediterránea (Kindersley, 2008, p. 81). Las hojas de acanto, "fue un motivo muy usado en la arquitectura y el diseño clásicos. Sus hojas simbolizan la sabiduría y las artes [...] asociado a la inmortalidad". Porque "los héroes han triunfado sobre las dificultades de su labor" (Chevalier \& Gheerbrant, 1986, p. 47).

La difusión estética del neoclasicismo europeo, alcanza no solamente a la arquitectura civil provinciana puneña si no también a elementos utilitarios de tradición autóctona como los keros, correspondientes a este periodo,"el fenó-

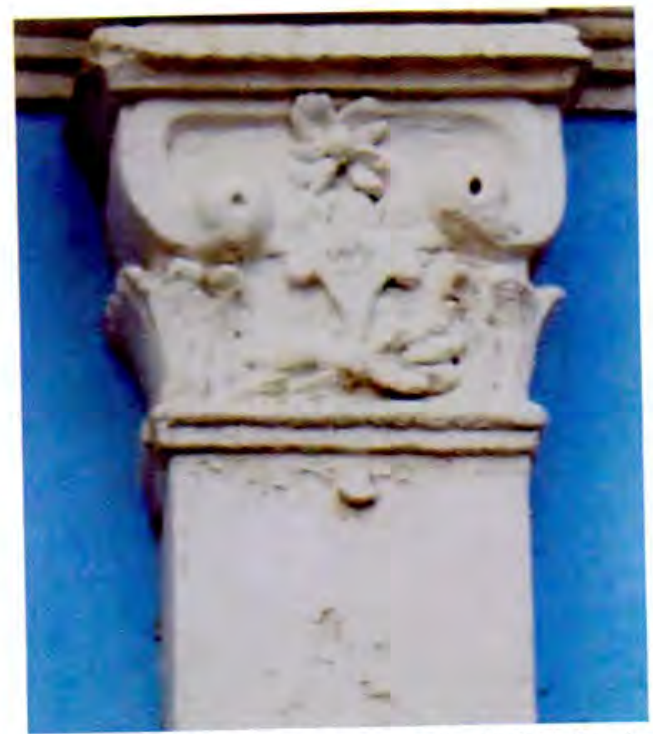

Figura 3. Capitel Compuesto del Colegio Gran Unidad Nacional San Carlos Puno. Abril 2014. 


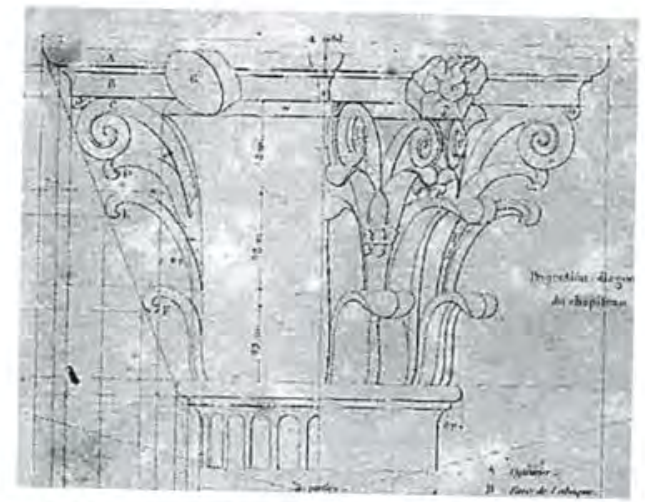

Figura 4. Capitel Corintio (Detalle).

Fuente: Barozzio de Vignole (s/f).

meno de la difusión considerada como aculturación no es meramente una trasferencia de bienes culturales de una sociedad a otra [...], a lo largo del tiempo y en el marco del ámbito territorial concreto, lo que permite tener un instrumento sumamente valioso e ilustrativo a la hora de establecer comparaciones interculturales e interestilísticas" (Alcina, 1998, p. 131).

La recreación ingenua de hojas de acanto en los keros CMD008, CMD012, CPA002, CPA004, CPA007, da cuenta que el neoclasicismo pierde su rigor académico en el altiplano puneño, pero lo inscribe en un momento histórico, el poblador andino creador y usuario del kero, interpreta desde su propia realidad los nuevos conceptos republicanos y estéticos.
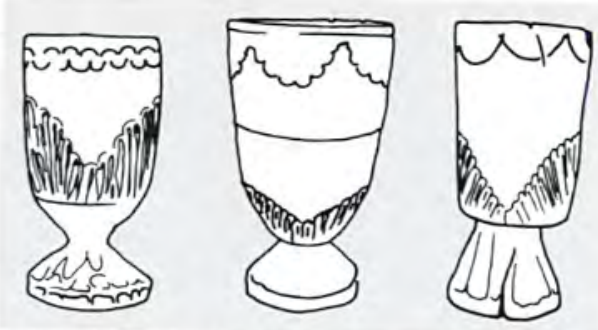

KERO - CPA002. KERO - CPA004. KERO - CPA007.

Figura 6. Recreación ingenua de hojas de acanto en keros.

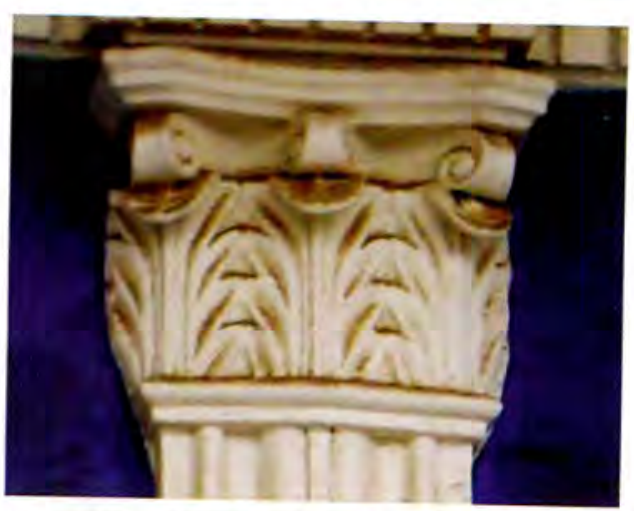

Figura 5. Capitel Corintio de vivienda particular adyacente al Parque Pino Puno. Abril 2014.

La banda ondulante en el borde superior de los keros CMD008, CMD012, CPA002, CPA004, CPA007, inherente al estilo de keros republicanos con hojas de acanto, como modelo pre establecido.

El kero republicano con iconografía de la hoja de acanto también da cuenta del cambio de forma.

A partir del kero datado por Natalia Majluf, como republicano, de copa con doble franja - anillo en alto relieve y basa, podemos afirmar que algunos Keros republicanos poseen estas características formales, equiparables a los queros CPA005, CPA009, CPA013. (Figura 8).

\section{c. Ícono franja lineal, zigzagueante, rombos eslabonados y hojas.}

Los keros incaicos fueron vasos de madera con decoración geométrica estilizada, lineal incisa, además de figuras toscas de llamas y aves ordenadas dentro de campos horizontales; estos campos horizontales pasarán con los keros de transición a ser escenas narrativas figurativas, con diseños más realistas y polícromos, producto de la invasión visual europea. "Los queros de la transición muestran como sus mayores transformaciones decorativas un aumento en la imaginería 


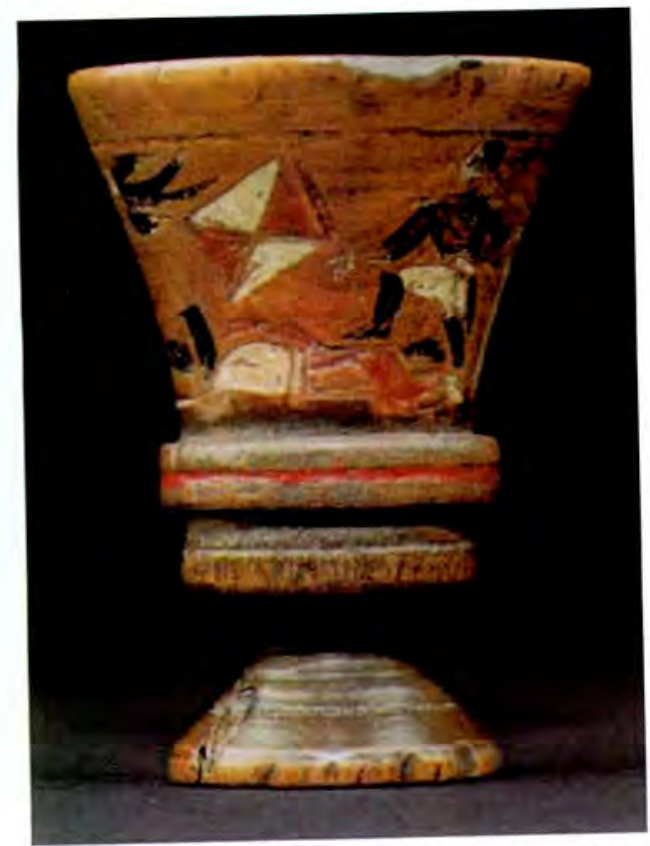

Figura 7. Kero de madera mostrando a un soldado patriota.

Fuente: Majluf (2006, p. 236).

figurativa pintada [...] aparecen orientados a lo largo de una o más bandas horizontales" (Lizarraga, 2009, p. 43).

Los keros republicanos, mantienen como rezago de los campos o bandas horizontales de decoración del kero inca y de transición; una franja zigzagueante dentro de una doble franja - anillo, kero CPA008, CPA009, CPA013 (figura 9), excepcionalmente se aprecia otro tipo de íconos como franjas, rombos eslabonados y hojas.

A un despojo de todo elemento
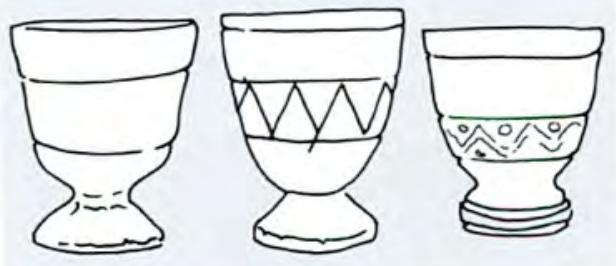

KERO - CPA005. KERO - CPA009. KERO - CPA013.

Figura 8. Íconos franja lineal, zigzagueante gráfico para sólo conservar estas franjas lineales, como único ícono decorativo, aparte de la forma del Kero CPA001, CPA005, CPA006, CPA010, CPA011, CPA012, CPA014, CPA015, CPA017.

\section{Variaciones estilísticas}

La investigación, se centró en el análisis, iconológico de los keros, habiendo realizado la caracterización detallada de forma e íconos; presentamos la interpretación y comprensión iconológica, que permite determinar variaciones estilísticas, método que permite situar temporalmente creaciones estéticas, los cambios estilísticos están en función del tiempo y el espacio debido a la influencia de factores políticos, sociales y económicos sobre el creador de la obra de arte.

El estilo artístico permite establecer "nexos de carácter histórico-cultural a través del tiempo y el espacio territorial. [...] que permite tener un instrumento sumamente valioso e ilustrativo a la hora de establecer comparaciones interculturales o interestilísticas" (Alcina, 1998, p. 131). Lo que permitirá establecer secuencias de variaciones estéticas de forma cronológica.

En la tabla 3 se aprecia las variaciones estilísticas del kero, en donde se aprecia una evolución de la forma clásica (Troncocónica invertido) del kero, a la representación occidental de la copa (Copa, fuste integro y basa).
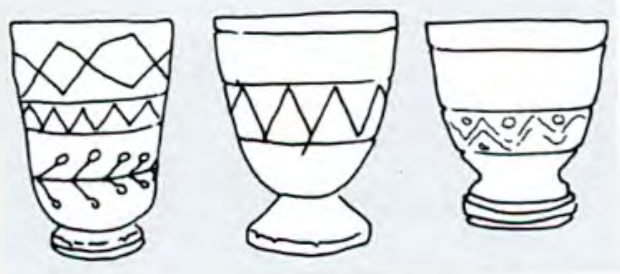

KERO - CPA008. KERO - CPA009. KERO - CPA013.

Figura 9. Íconos franjas, zigzagueante, rombos eslabonados y hojas 
En base al análisis estilístico de los keros, se determinó los procesos de difusión de estilos respecto a otros, secuencias históricas por tiempo y espacio estableciendo una cronología.

Podemos establecer que los keros coloniales, son principalmente vasos troncocónicos de madera policromada, compuesta de iconografía de escenas temáticas, tocapus y flores de cantuta; y que los keros republicanos, son principalmente copas de madera compuesta de iconografía de hojas de acanto.

Se evidencia una transición de la forma y el ornato del kero colonial hacia el kero republicano, lo que determina un cambio de expresión en la forma y ornato del kero colonial del periodo colonial tardío a inicios de la república. (Figura 10).

\section{Sobre la transición de la forma y ornato del kero.}

Se evidencia la desaparición de la policromía e iconografía de inspiración inca plasmada en los keros de la región Puno, su expresión está constituida por su forma y ornato, es así que los keros coloniales son principalmente vasos troncocónicos de madera policromada, compuesta de iconografía de escenas temáticas, tocapus y flores de cantuta. El periodo comprendido entre los siglos XVI - XVIII significó para la población andina entre otras cosas, un choque epistemológico en la manera de percibir lo propio de la imagen, dado que tanto las fuerzas hispanas como las sociedades nativas del siglo XVI desarrollaron distintos conceptos y lógicas de representación pictórica. La imposición hispana de los nuevos códigos visuales repercutió en los keros coloniales, constituyéndolos como respuesta al dominio cultural, religioso del imaginario colectivo, en un "arte de la memoria" inca (Lizárraga, 2009, p.37).

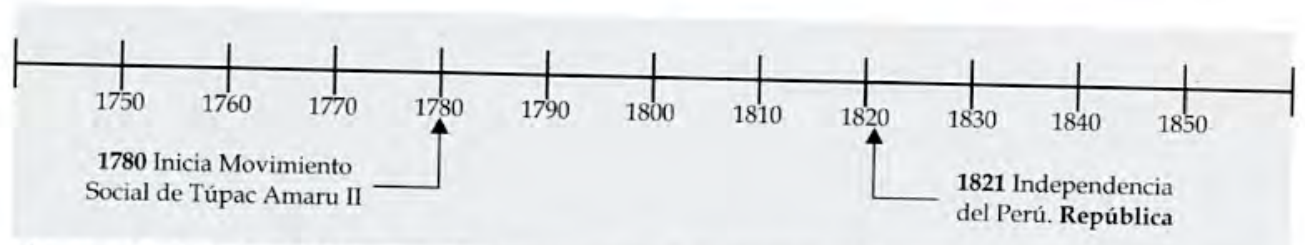

Figura 10. Escala del tiempo de la transición histórica del Kero colonial y republicano

Tabla 3. Variaciones estilísticas del Kero

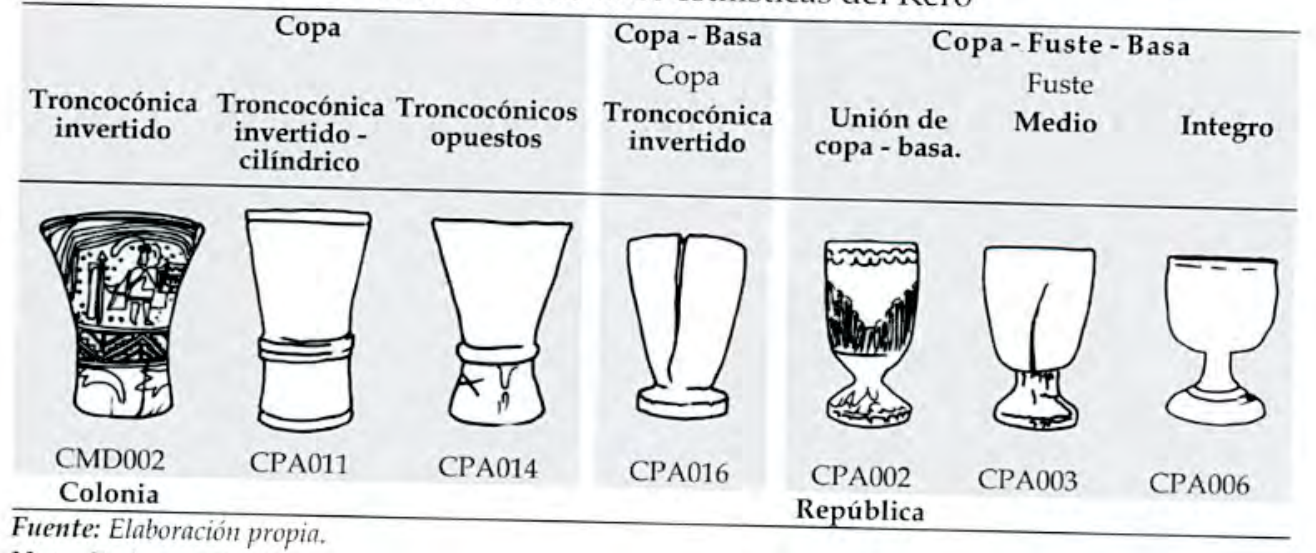

Nota: En base a tabla 2. 
La supervivencia de lo Inca como concepto se debió a que era indispensable su filiación para los caciques porque gracias a ello ostentaban su poder, por tanto, durante el periodo colonial fueron estos linajes incas los únicos capacitados, con poder y recursos, para seguir materializando las respectivas memorias de sus antepasados, utilizado con fines ceremoniales, de hospitalidad y así mantener la cohesión política y administrativa. Después de 1781, con la eliminación de muchos cacicazgos rebeldes, se evidenció una transición de la forma y el ornato del kero colonial; los lentos procesos que terminarán el 4 de julio de 1825 con la extinción por completo del título de cacique por Bolívar, da paso al kero republicano con su forma de copa, e iconografía de hojas de acanto en su ornato.

Se aprecia las variaciones estilísticas de la forma del kero, de la forma clásica troncocónica invertido del kero colonial, hacia la representación occidentalizada de copa del kero republicano, determinando un cambio de expresión en la forma y ornato del kero del periodo colonial tardío a inicios de la república. En la región Puno se evidencia una limitada expresión de los keros después del movimiento de Túpac Amaru II.

En consecuencia, la etnoplástica como efecto de las medidas políticas después del movimiento social de Túpac Amaru II en la región Puno tuvo consecuencias negativas en su expresión, principalmente en los textiles y keros.

\section{CONCLUSIONES}

Se evidencia la desaparición de la policromía e iconografía inca plasmada en los keros del altiplano de Puno, lo que determinó un cambio de expresión en la forma y ornato del kero colonial tardío a inicios de la república. Los keros coloniales fueron predominantemente vasos troncocónicos de madera policromada, compuesta de iconografía de escenas temáticas, tocapus y flores de cantuta; mientras que los keros republicanos, fueron principalmente copas de madera compuesta de iconografía de hojas de acanto.

Tanto el kero colonial como el kero republicano (inicial) poseen en sus formas y ornatos características precisas.

La transición de la forma y el ornato del kero colonial al kero republicano, se produce por efecto de la prohibición del uso del kero, elemento utilitario ancestral inca en su expresión de forma y ornato, como medida política para restablecer el orden colonial después del movimiento social de Tupac Amaru II.

\section{REFERENCIAS BIBLIOGRÁFICAS}

Alcina, J. (1998). Arte y antropología. Madrid, España: Alianza Editorial.

Barozzio de Vignole, J. (s/f). Traité Elémentaire Practique D'Architecture ou Étude des Cinq Ordres. Garnier Fréres, Paris: Libraires -Éditeurs.

Bertonio, L. (1956). [1612] - Vocabulario de la lengua aymara. La Paz Bolivia: Litografía Don Bosco.

Bertonio, L. (2004). [1612] - Vocabulario de la lengva aymara. Arequipa, Perú: El lector.

Cahill, D. (2006). El visitador general Areche y su campaña iconoclasta contra la cultura andina en Visión y símbolos del virreinato criollo a la república - Colección Arte y Tesoros del Perú. Lima, Perú: Banco de Crédito.

Cummis, T. (2003). Imitación e invención en el barroco peruano en $\mathrm{El}$ Barroco Peruano 2- Colección Arte y Tesoros del Perú. Lima, Perú: Banco de Crédito. 
Chevalier, J. \& Gheerbrant, A. (1986). Diccionario de los símbolos. Barcelona, España:Herder.

Kindersley, D. (2008). Signos y símbolos. China: Dorling Kindersley.

Gisbert, T. (2008). El paraíso de los pájaros parlantes - la imagen del otro en la cultura andina ( $3^{\text {a }}$. ed.). La Paz, Bolivia: Plural Editores.

Gisbert, T. (2006). Arte textil y mundo andino. Tercera edición. La Paz, Bolivia: Musef editores.

Golte, J. (1980). Repartos y rebeliones. Túpac Amaru y las contradicciones de la economía colonial. Lima, Perú: Instituto de Estudios Peruanos.

Gonzalez Holguín, D. (1989) [1608]. Vocabulario de la lengua general de todo el Perú llamada lengua qquichua o del inca, 707p.; Lima Perú: Universidad Nacional Mayor de San Marcos. Presentación de Ramiro Matos Mendieta. Prólogo de Raúl Porras Barnechea.

Horta, H. (2013). Queros de madera del Collasuyo: nuevos datos arqueológicos para definir tradiciones. en Estudios Atacameños N²45. P95-116.

Koun Arce Elizabeth. (2003) Los qeros en el marco del barroco andino en Memoria del I encuentro internacional - Barroco Andino. La Paz, Bolivia: Unión Latina.

Lizarraga, M. A. (2009). Las élites andinas coloniales y la materialización de sus memorias particulares en los "queros de la transición" (vasos de madera del siglo XVI) en Boletín del Museo Chileno de Arte
Precolombino vol. $14, \mathrm{~N}^{\circ} 1,2009$, pp. 37-53, Santiago de Chile

Majluf, N. (2006). Los fabricantes de emblemas. Los símbolos nacionales en la transición republicana. Perú, 1820 - 1825 en Visión y símbolos del Virreinato criollo a la República - Colección Arte y Tesoros del Perú. Lima, Perú: Banco de Crédito.

Matos, R. (1999). La cerámica inca en Los Incas - Arte y símbolos. Lima, Perú: Banco de Crédito del Perú.

Parramón. (2002). Como reconocer estilos. (4^.ed.). Barcelona, España: Parramón Edición, S.A.

Sabogal, J. (1952). El kero - vaso de libaciones cuzqueño de madera pintada. Lima, Perú: Editorial del Museo de la Cultura Peruana.

Fray. Santo Tomas, Domingo de. (2006) [1560] - Lexicón, o Vocabulario de la lengua general del Perú. Lima, Perú: ElSanto Oficio-Códice Ediciones.

Urquiza, A. \& García, J. E. (2012). La construcción historiográfica del Arte. Madrid, España: Centro de Estudios Ramón Areces, S.A.

Vera Bejar, W. E. (2008). Puno: La Heredera de San Luis de Alba. Puno, Perú: Universidad Nacional del Altiplano-Puno.

Walker, Ch. (1989). El estudio del campesino en las ciencias sociales peruanas en Alpanchis - Poder y Autoridad en los Andes Año XXINo33- Primer semestre 1989. Lima, Perú: Asociación Gráfica Educativa, Tarea. 